OPEN ACCESS

Edited by:

Daishu Han,

Chinese Academy of Medical Sciences and Peking Union Medical College, China

Reviewed by: Suresh Yenugu,

University of Hyderabad, India Rachel Guiton, Université Clermont Auvergne, France

*Correspondence: Andreas Meinhardt Andreas.meinhardt@ anatomie.med.uni-giessen.de

Christiane Pleuger

Christiane.pleuger@ anatomie.med.uni-giessen.de

Specialty section: This article was submitted to Mucosal Immunity, a section of the journal

Frontiers in Immunology

Received: 27 August 2020 Accepted: 03 November 2020 Published: 27 November 2020

Citation:

Pleuger C, Silva EJR, Pilatz A, Bhushan S and Meinhardt A (2020) Differential Immune Response to Infection and Acute Inflammation Along the Epididymis.

Front. Immunol. 11:599594. doi: 10.3389/fimmu.2020.599594

\section{Differential Immune Response to Infection and Acute Inflammation Along the Epididymis}

\author{
Christiane Pleuger ${ }^{1,2 *}$, Erick José Ramo Silva ${ }^{3}$, Adrian Pilatz ${ }^{2,4}$, Sudhanshu Bhushan ${ }^{1,2}$ \\ and Andreas Meinhardt ${ }^{1,2 *}$ \\ ${ }^{1}$ Institute of Anatomy and Cell Biology, Justus-Liebig-University Giessen, Giessen, Germany, ${ }^{2}$ Hessian Centre of \\ Reproductive Medicine, Justus-Liebig-University Giessen, Giessen, Germany, ${ }^{3}$ Department of Biophysics and \\ Pharmacology, Institute of Biosciences of Botucatu, São Paulo State University (UNESP), Botucatu, Brazil, ${ }^{4}$ Department of \\ Urology, Pediatric Urology and Andrology, University Hospital, Justus-Liebig-University Giessen, Giessen, Germany
}

The epididymis is a tubular structure connecting the vas deferens to the testis. This organ consists of three main regions-caput, corpus, and cauda-that face opposing immunological tasks. A means of combating invading pathogens is required in the distally located cauda, where there is a risk of ascending bacterial infections originating from the urethra. Meanwhile, immune tolerance is necessary at the caput, where spermatozoa with immunogenic neo-antigens originate from the testis. Consistently, when challenged with live bacteria or inflammatory stimuli, the cauda elicits a much stronger immune response and inflammatory-inflicted damage than the caput. At the cellular level, a role for diverse and strategically positioned mononuclear phagocytes is emerging. At the mechanistic level, differential expression of immunoprotective and immunomodulatory mediators has been detected between the three main regions of the epididymis. In this review, we summarize the current state of knowledge about regionspecific immunological characteristics and unveil possible underlying mechanisms on cellular and molecular levels. Improved understanding of the different immunological microenvironments is the basis for an improved therapy and counseling of patients with epididymal infections.

Keywords: epididymis, epididymitis, mononuclear phagocytes, uropathogenic $E$. coli, infertility, bacterial infection

\section{STRUCTURE AND FUNCTION OF THE EPIDIDYMIS}

The epididymis is connected to the rete testis via efferent ducts that converge onto one single epididymal duct in the initial segment opposite the mediastinum testis. The epididymal duct meanders through three regions known as the caput (which contains the initial segment in rodents), corpus, and cauda epididymides (Figure 1A). Connective tissue septae segregate the epididymis further, producing 10 segments in mice (1) and 19 in rats (2). Septae in the human epididymis are present but poorly defined (3). The duct is lined by a two-layered pseudostratified epithelium, consisting of principal, basal, narrow/clear cells, and resident immune cells [mononuclear phagocytes (see Immune-Cell Populations in the Rodent Epididymis) and "halo cells" $(4,5)]$ and surrounded by a wall composed mostly of smooth muscle cells (Figures 1B, C). The interstitium is composed of blood vessels, 


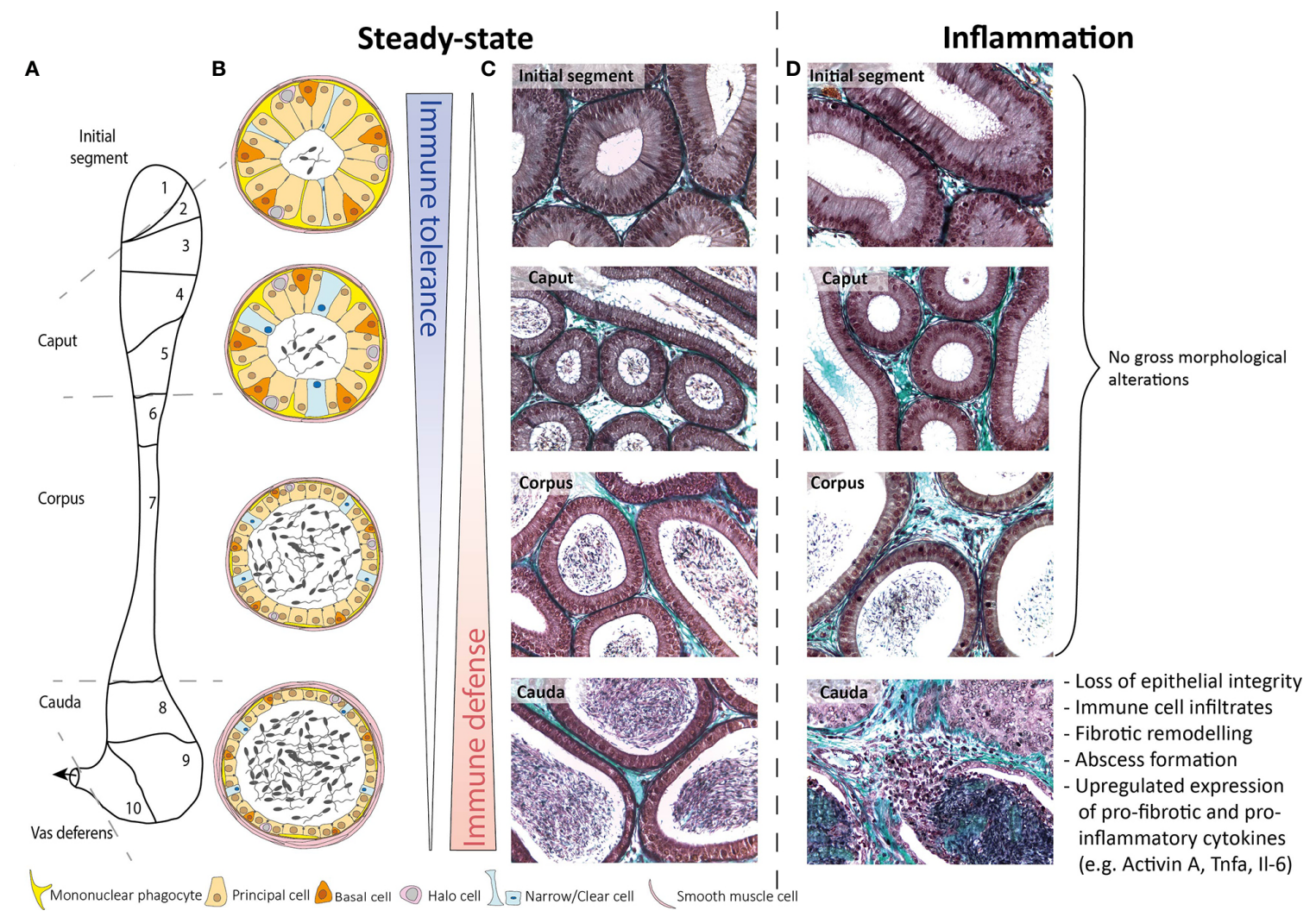

FIGURE 1 | Schematic overview of murine epididymal regions during steady-state and inflammatory conditions. (A) Based on structure and function, the murine epididymis is principally compartmentalized into four distinct anatomical regions, i.e. the initial segment (segment 1), caput (segments 2-5), corpus (segments 6-7), and cauda (segments 8-10). (B) The epididymal epithelium consists of diverse cell types, namely principal cells, basal cells, halo cells, and clear/narrow cells, whereby the epithelial composition and lumen diameter changes along the length of the single duct. To fulfill the main immunological functions-immune tolerance in the proximal regions and immune defense in the distal regions-mononuclear phagocytes are strategically positioned between adjacent epithelial cells and exhibit long protrusions within the initial segment, which are gradually shrinking towards the distal regions. (C, D) Under inflammatory conditions (10 days after infection with uropathogenic $E$. coll), the epididymis shows striking different immunological responses. While the initial segment, caput, and corpus remain mostly unaffected, the cauda epididymidis undergoes dramatic morphological alterations. Masson-Goldner-Trichrome staining, primary magnification 40x.

lymphatic vessels, leukocytes, and loose connective tissue, which increases in density in the septae. The luminal fluid provides a milieu necessary for the step-wise maturation of spermatozoa required to achieve full fertilizing capacity $(6,7)$. The bloodepididymal-barrier (BEB) - extending apically between adjacent principal cells-maintains the unique composition of the luminal fluid. However, its role in protecting spermatozoa from immune attack is likely not as robust as the blood-testis-barrier (8).

Emerging evidence on cellular and molecular levels has resulted in the hypothesis that the epididymis is "a series of organs side-byside" (9). This hypothesis is evidenced by particular region-specific characteristics in regards to (a) the composition of the epithelium (4, $5)$, (b) the distribution and phenotype of resident immune cells subpopulations (10-13), and (c) differential gene expression profiles $(1,2,14,15)$. In line with that, septae segregate different segments and have been demonstrated to function as diffusion barriers, possibly creating distinct interstitial microenvironments $(16,17)$.

From the immunological perspective of the hypothesis that the epididymis is a "series of organs side-by-side," this duct faces two different immunological challenges at its opposing ends
(Figure 1B). At the proximal end, mechanisms of strong local tolerance are required to avoid autoimmune reactions against post-testicular spermatozoa expressing sperm-specific neoantigens (18). Conversely, at the distal end, mechanisms are required to react against bacterial pathogens ascending from the urethra (19). As pointed out below, there is accumulating evidence that different subsets of resident immune cell populations exist throughout the length of the epididymis that may play a role in the balance of immune tolerance and immune defense at the opposing ends of this organ.

\section{LEUKOCYTES IN THE NORMAL EPIDIDYMIS}

\section{Immune-Cell Populations in the Rodent Epididymis}

Different immune-cell populations, including heterogenous subsets of the mononuclear phagocyte (MP) system, T and B 
lymphocytes reside within the rodent epididymis $(4,10,11,13$, 18, 20-23). Two different T-cell populations [CD4-CD8- (DN) and $\gamma \delta$ T cells] have been identified recently: DN T cells are more abundant within the caput while $\gamma \delta$ T cells are evenly distributed throughout the entire epithelium and interstitium (11). A regionspecific role for these subpopulations remains elusive.

Generally, tissue-resident MPs are considered "guardians of the immune system," often found located at the interface with the external environment. MPs comprise heterogeneous subsets of monocytes, macrophages, and dendritic cells (DCs), which have a broad spectrum of common characteristics (i.e. migratory capabilities towards gradients of microbial signals or chemokines, engulfment and processing of microbial fragments or dying cells and antigen-presentation to the adaptive immune system, secretion of signaling molecules). Most notably, MP subsets are highly plastic, allowing them to regulate tissue homeostasis and immune responses in an organ-specific manner.

Within the epididymis, MPs constitute the majority of resident immune cells and comprise multiple closely related subpopulations that are strategically positioned throughout the different regions. As the composition and phenotype of epididymal MPs under normal circumstances has been comprehensively summarized elsewhere $(24,25)$, only a brief reflection will be provided here serving as a prerequisite to understand alterations seen in infection and inflammation. In brief, distinct MP populations at the periphery of the epithelium and within the interstitium are arranged as dense network with the highest abundance in the initial segment (IS). They are characterized by the expression of the chemokine (C-X3-C motif) receptor $1\left(\mathrm{CX}_{3} \mathrm{CR}_{1}\right)$ as well as a region-specific morphology and transcriptomic signature $(10,13,24)$. While peritubular $\mathrm{CX}_{3} \mathrm{CR}_{1}{ }^{+}$cells within the IS exhibit long arborizations between adjacent epithelial cells towards the tight junctions of the BEB, these gradually decline towards the distal segments until the cells finally appear flat in the cauda [Figure $1 B$ (13)]. Interstitial MP do not exhibit a stellate morphology. Rather, they can be differentiated by their expression of the macrophage mannose receptor CD206 and lack of CD11c, pointing to a macrophage phenotype (13).

Epididymal MPs are currently classified into different subtypes based on the expression of surface markers traditionally used to distinguish macrophages from DCs $(10,13)$, i.e. the high-affinity IgG receptor Fc $\gamma \mathrm{R}$ CD64 vs. integrin alpha X CD11c expression, respectively $(26,27)$. However, several subsets have been described to express a complex combination of these markers in association with other markers $\left(\mathrm{CX}_{3} \mathrm{CR}_{1}, \mathrm{CD} 11 \mathrm{~b}, \mathrm{~F} 4 / 80\right)(10)$. Thus, the original classification for epididymal MPs requires further consideration, with the benefit of techniques such as single cell RNA-sequencing and lineage tracing, to ultimately clarify the full extent of MP heterogeneity. Indeed, a recently published transcriptomic analysis revealed distinct gene expression profiles of $\mathrm{CX}_{3} \mathrm{CR}_{1}{ }^{+} \mathrm{MPs}$ isolated from different epididymal regions (10) suggesting a considerable level of MP heterogeneity and microenvironment-specific functions beside archetypical functions in all regions (i.e. phagocytosis and antigenpresentation). As an example, $\mathrm{CX}_{3} \mathrm{CR}_{1}{ }^{+} \mathrm{MPs}$ within the IS are differentially enriched with transcripts required for leukocyte transendothelial migration and cell adhesion (see below). Meanwhile, $\mathrm{CX}_{3} \mathrm{CR}_{1}{ }^{+} \mathrm{MPs}$ within the cauda are characterized by transcripts associated with NF-kappa B signaling, indicative of their protective role against invading luminal pathogens (10). Intriguingly, while both tubule-associated and interstitial MPs within the highly vascularized proximal regions (in particular the IS) can capture and process circulatory antigens, only interstitial MPs exhibit these properties in the more scarcely vascularized cauda (10). These spatial differences prompt the hypothesis that in the caput intraepithelial MPs could be involved in the continued capture of sperm autoantigens to maintain tolerance, while both the interstitially located MPs in the caput and cauda shall restrict microbial dissemination into the organ.

\section{Immune-Cell Populations in the Human Epididymis}

In contrast to experimental animals, human data on the epididymal leukocyte population are scarce and are almost exclusively derived using immune-based morphological methods (28). Human intraepithelial lymphocytes and macrophages are similar in terms of location to those found in rodents (29). Macrophages are the predominant immune cell population-except for intraepithelial leukocytes where $\mathrm{T}$ lymphocytes exceed-and express major histocompatibility complex class II (MHC-II) proteins in the interstitium. B cells are barely detectable, while DC consist of immature DC in the normal epididymis $\left[\mathrm{CD} 1 \mathrm{a}^{+} \mathrm{DC}, \mathrm{CD} 11 \mathrm{c}^{+}\right.$myeloid DC (mDC), and $\left.\mathrm{CD}_{209^{+}} \mathrm{DC}\right](30,31)$. Plasmacytoid DC and $\mathrm{CD} 3^{+}$mature DC are only found in chronic epididymitis, similar to $\mathrm{CD} 4^{+} \mathrm{Th} 17^{+} \mathrm{T}$ lymphocytes (30). Although not entirely clear, MHCII-restricted $\mathrm{CD}^{+} \mathrm{T}$ lymphocytes seem to represent the predominant phenotype of $\mathrm{T}$ cells in the interstitium. As in other organs, $\mathrm{CD} 8^{+} \mathrm{T}$ cells are the predominant phenotype in the epithelium and increase distally in the epididymis (31-33).

\section{THE EPIDIDYMAL RESPONSE TO INFECTION AND INFLAMMATION}

Various in vivo and in vitro models have clearly pointed to striking region-specific differences in the epididymal immune response. The clearest observation is that the cauda epididymidis is much more sensitive to inflammatory-inflicted damage than the caput epididymidis [Figure 1D (14, 34, 35)]. These observations are complemented by data from patients with acute bacterial epididymitis where in most cases the cauda is predominantly impacted, particularly in severe cases when an abscess is diagnosed (36).

\section{Region-Specific Responses in Human Epididymitis}

Acute epididymitis affects $\sim 250$ to 650 per 100,000 men each year (37). Three different forms can be distinguished: i) bacterial ascension through the male accessory glands (the most common 
form), ii) concomitant epididymitis in the context of viral orchitis, and iii) a primarily viral epididymitis.

Molecular microbiological diagnostics can identify a causal bacterial pathogen in $87 \%$ of antibiotic-naïve cases (36). Both typical urinary tract pathogens [Escherichia coli (E. coli)] and sexually transmitted bacteria (Chlamydia trachomatis, Neisseria gonorrhoeae) are most relevant, regardless of age [Figure 2 (36)]. As a result of bacterial ascension, $44 \%$ of patients experience isolated pain in the cauda epididymidis, $41 \%$ experience pain in the entire epididymis, and only $15 \%$ report isolated pain in the caput epididymidis (36). Abscess formation characterizes clinically severe forms of the disease. Interestingly, abscesses are typically located in the cauda, and very rarely in the caput epididymidis (36). Early studies that collected diagnostic epididymal biopsies identified polymorphonuclear cells in $\sim 54 \%$ of cases and somewhat less frequently lymphocytic infiltrates (38). Of note, no differentiation of the inflammatory response in dependence of the etiology of the most relevant pathogens (e.g. E. coli vs. Chlamydia trachomatis) was ever conducted in human specimens. Research of this kind is limited by the low availability of specimens as histological evaluation is only performed in cases with a fulminant course, where secondary testicular infarction with the necessity of semicastration occurs (36). Finally, persistent epididymal enlargement (usually of the cauda) $>3$ months post infection affects $\sim 16 \%$ of patients (36).

Concomitant epididymitis in primary viral orchitis is possible both synchronously and metachronically, but the frequency is unclear. Data only exist for mumps orchitis from the era before mumps vaccination, and when scrotal ultrasound was unavailable (39). Currently, only one study has used ultrasound to describe the involvement of the epididymis in 23 cases of mumps orchitis. Interestingly, in $45 \%$ of the cases, no epididymal changes were visible (isolated orchitis), while in $30 \%$ only the caput was affected (diameter $11.1 \mathrm{~mm}$ instead of $6.5 \mathrm{~mm}$ ) and in another $26 \%$ the entire epididymis was affected (40). These findings are in stark contrast to those of bacterial epididymitis, where the cauda is always primarily affected.

Only few studies carried out virological examinations in epididymitis patients. In a study investigating 28 epididymal biopsies, arbor and rhinoviruses were detected in only three cases (38); unfortunately corresponding histological reports were lacking. With epididymal biopsies now obsolete due to the risk of obstruction, another study isolated enteroviruses directly from the semen of patients with acute epididymitis and considered this as the etiologic pathogen (36). Moving forward, PCR-based urine diagnostics (STIs and 16s rDNA) are now recommended in the case of antibiotic pre-treatment with negative urine culture, while PCR diagnostics should be performed directly from the ejaculate if viral genesis is suspected (36).

\section{Region-Specific Immune Responses in Rodent Models of Acute Bacterial Epididymitis}

A frequently used rodent model to mimic ascending acute bacterial epididymitis uses uni- or bilateral intravasal inoculation of uropathogenic E. coli [UPEC, (19)]. After infection, fundamentally disparate immune responses and associated immunopathologies were observed in different epididymal regions (Figures 1C, D). The caput epididymidis remains mostly unaffected throughout the course of infection
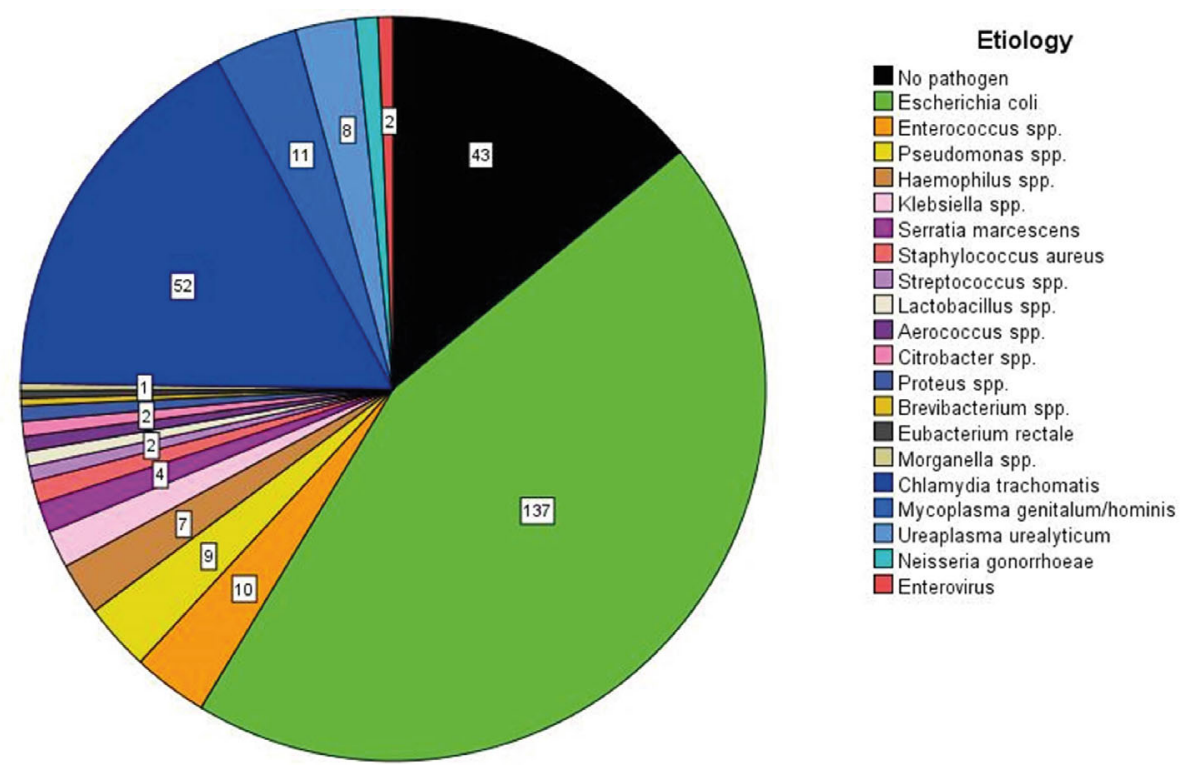

FIGURE 2 | The etiology of acute epididymitis in 284 patients without antimicrobial pre-treatment. A total of 307 pathogens are visualized due to two specimens being simultaneously detected in 23 patients. The pathogen detection rate is $85 \%$ with $E$. coli as the most common pathogen, followed by Chlamydia trachomatis as second most common. Data are obtained from a prospective study running since 2007 [modified according to (36)]. 
despite the presence of bacteria and the expression of signaling molecules required to sense bacteria and mount inflammatory responses against them [see Region-Specific Immune Responses to LPS-Induced Epididymitis (14, 34)]. Similar region-specific immune reactions have also been observed in a mouse model of experimental autoimmune epididymo-orchitis (35).

\section{Immunotolerance in the Caput Epididymidis}

A possible explanation for different immune responsiveness could lie in the unique requirements of the immune environment of the caput. Here, neoantigen-expressing spermatozoa originate from the immune-privileged testicular environment. As a result, multiple complementary mechanisms of peripheral immune tolerance are established to prevent autoimmune reactions against spermatozoa. At the cellular level, intraepithelial MPs sample sperm neoantigens via their characteristic thin protrusions (see Immune-Cell Populations in the Rodent Epididymis) that reach the epididymal lumen and-after migration to draining lymph nodes-induce regulatory $\mathrm{T}$ cells to suppress effector $\mathrm{T}$ cells (41). Although this mechanism was observed in men after vasectomy and may not reflect the steady-state situation, support for a more general mechanism in epididymal function has been obtained in the gut, an organ that faces similar challenges in inducing peripheral tolerance. In the gut, $\mathrm{CX}_{3} \mathrm{CR}_{1}{ }^{+}$macrophages (located within the lamina propria) capture luminal antigens and transfer them to $\mathrm{CD}_{103}{ }^{+} \mathrm{DC}$ in a connexin43-dependent manner (42). $\mathrm{CD}_{103}{ }^{+} \mathrm{DC}$, in turn, migrate through lymphatics to the draining lymph node to induce the differentiation of antigen-specific regulatory $\mathrm{T}$ cells $(42,43)$.

In addition, MPs residing in the IS are in close contact with neighboring epithelial cells and possess a strong capacity to resolve arising inflammation - as shown by the rapid clearance of damaged epithelia (44). These and other means to preserve epithelial integrity are important mechanisms to maintain peripheral tolerance as a loss of epithelial integrity in the IS promotes autoimmuneassociated responses against sperm antigens as seen in mice lacking the adhesive protein milk fat globule-EGF factor 8 protein MFGE8 (also known as SED1 or lactadherin) (45). Moreover, an important role for regulatory $\mathrm{T}$ cells was postulated in epididymal immune tolerance as depletion of these cells allowed induction of experimental auto immune-orchitis, at least under certain conditions (vasectomized B6AF1 mice) (46).

Molecular data point to the necessity to preserve immunotolerance not only in the IS and caput, where sperm first enter the epididymis, but throughout the organ. Here, it seems that transforming growth factor-beta (TGF $\beta$ ) family members have a prominent role. TGF $\beta$ isoforms (TGF- $\beta 1$, TGF- $\beta 2$, TGF$\beta 3)$ are expressed in all epididymal regions, but the active forms are preferentially found in the corpus (47). All isoforms activate the same receptor complex (TGF $\beta$ receptor 1 and 2) (48). Mice with DC-specific TGF $\beta$ receptor 2 deficiency develop severe leukocytosis in all regions, including the IS, which is triggered by an immune response specifically targeting sperm antigens (18).

Other immunomodulatory molecules, such as indolamine 2,3-dioxygenase [IDO (49)] or activin (50) are mostly enriched in the proximal region. Further protective mechanism in the proximal region of the epididymis could be based on the high expression of a large number of various anti-microbial peptides $(51,52)$. These include beta-defensins (Defb 3, 12, 15, 18, 20, 30, 42), lipocalin 2 ( Lcn2), cathelicidin (Camp), pentraxin 3 (Ptx3), and Lypd8 (Ly6/Plaur domain -containing protein 8). All of them were found in the top 50 significantly differential expressed genes with high baseline expression in the normal caput epididymis using whole transcriptome analysis (14). While beta-defensins are mostly expressed by epithelial cells, including proton-secreting clear cells with protrusions reaching into the lumen (53) for other anti-microbial peptides their cellular origin in the epididymis is not established, e.g. those controlling infection with gram-negative bacteria ( $L c n 2, L y p d 8)$. It needs to be noted though that other defensins such as Defb 1, 2, and 9 are expressed at much higher levels in the cauda. This indicates a complex multitude of mechanisms that contribute to the maintenance of peripheral tolerance, whilst simultaneously providing sufficient resistance to bacteria-induced damage [reviewed in (54)], it is not clear to what extend their differential distribution contributes to immune tolerance and a dampened immune response towards microbes preferentially in the proximal epididymis.

\section{Immune Defense in the Cauda Epididymidis}

Conversely, the cauda is highly susceptible to damage as a result of inflammatory responses. UPEC-infected mice are characterized by interstitial and intraluminal immune cell infiltrates, epithelial detachment, and fibrosis that all contribute to irreversible epididymal duct obstruction [Figure 1D $(14,34)$ ]. The immunopathological damage gradually decreases towards the corpus epididymidis. Besides the transcriptional differences underlying the immune responsiveness of epididymal MPs (10), segmental barriers serve to restrict the ascent of pathogens and spread of inflammatory modulators, at least for some time (16).

Intriguingly, the observed damage is mostly elicited by the magnitude of the host's immune response and only to a lesser extend due to bacterial virulence factors as evidenced by mice lacking the Myeloid Differentiation Primary Response Protein MYD88, which are characterized by a less pronounced immune reaction towards UPEC infection (34).

Although antibiotic interventions can eliminate epididymitisassociated pathogens, histopathological alterations and concomitant long-term fertility impairments are not preventable by antibiotics alone (55-59). However, a combined antibiotic (i.e. levofloxacin) and immunosuppressant (dexamethasone) regimen can successfully dampen adaptive (rather than innate) immune responses and the associated tissue damage in UPEC-induced mouse epididymitis (59). This treatment might thus constitute a promising strategy for fertility preservation in affected men (59).

\section{Region-Specific Immune Responses to LPS-Induced Epididymitis}

Considering the frequency of E. coli-induced epididymitis in men (see Region-Specific Responses in Human Epididymitis), lipopolysaccharide (LPS), a structural component of the outer membrane of Gram-negative bacteria such as E. coli, can be explored as agonist of the toll-like receptor 4 (TLR4) to investigate the role of TLR4 signaling in epididymitis 
pathogenesis. To study region-specific immune responses, LPS can be applied systemically to circumvent the temporally different exposures of the epididymal regions to the inflammatory challenge, as seen in models of ascending bacterial infection $(14,34)$. In rodents, TLR4 is expressed in epididymal epithelial cells, smooth muscle cells and interstitial macrophages (60-63). TLR4 and associated signaling molecules [i.e. MYD88, cluster differentiation 14 (CD14), TIR-domaincontaining adapter molecule-1 (TICAM1), and LPS-binding protein (LBP)] show a spatial expression pattern in the epididymis, adding further credence to region-specific inflammatory responses in the epididymis $(14,15,61,63,64)$.

The first demonstration that TLR4 activation by LPS was sufficient to elicit epididymitis came from a rat model of experimentally induced systemic endotoxemia (61). Intravenous LPS $(0.1-1.0 \mathrm{mg} / \mathrm{kg})$ injection triggered rapid inflammatory responses in the epididymis that were mediated by TLR4dependent NF-kappa B activation and an upregulation of inflammatory mediators [i.e. Il1b, Tnf, Nos2, Bdkrb1 (61, 65)]. Intraperitoneal LPS $(3.0 \mathrm{mg} / \mathrm{kg})$ injection in mice results in a similar upregulation of pro-inflammatory cytokines and induces morphological alterations (immune cell infiltrates, fibrosis) that are mostly restricted to the cauda epididymis (66). This response is absent from $\mathrm{Tnf}^{-1-}$ mice and wild-type mice treated with the TNF $\alpha$ inhibitor pomalidomide, indicating that the induced inflammatory response is the primary source of tissue damage (66).

Similar to the effects seen in the UPEC mouse model, retrograde intravasal LPS injection in rodents resulted in a severe inflammatory reaction within the cauda $(66,67)$. These responses were more robust than those generated by systemic LPS administration (66). Intriguingly, when LPS was directly injected into the mesenchyme of the caput epididymidis, this region was locally responsive as indicated by an upregulation of several members of interleukin, NF-kappa B, TNF families, and downregulation of $\beta$-defensins $(68,69)$.

The data from these studies point to the involvement of TLR4 signaling in mediating the immunopathological changes seen in acute bacterial epididymitis. However, the exact mechanism governing these events-such as the contributions of damageassociated molecular patterns (e.g. S100A) as enhancers (70), different TLR4-dependent signaling pathways (MYD88, TICAM), and downstream inflammatory mediators of epididymitis progression and severity-have only just begun to emerge.

\section{REFERENCES}

1. Johnston DS, Jelinsky SA, Bang HJ, DiCandeloro P, Wilson E, Kopf GS, et al. The mouse epididymal transcriptome: transcriptional profiling of segmental gene expression in the epididymis. Biol Reprod (2005) 73:404-13. doi: 10.1095/biolreprod.105.039719

2. Jelinsky SA, Turner TT, Bang HJ, Finger JN, Solarz MK, Wilson E, et al. The rat epididymal transcriptome: comparison of segmental gene expression in the rat and mouse epididymides. Biol Reprod (2007) 76:561-70. doi: 10.1095/ biolreprod.106.057323

3. Sullivan R, Mieusset R. The human epididymis: its function in sperm maturation. Hum Reprod Update (2016) 22:574-87. doi: 10.1093/humupd/ dmw015

\section{CONCLUSIONS}

The spatial differences in the structure and cellular composition of the epididymal epithelium and the region-specific gene expression patterns associated with sperm maturation are well known. Now, evidence is also accumulating to support a differential immune response throughout the epididymis. Most models point to a stronger inflammatory response to the same infectious or inflammatory challenges in the cauda compared to the caput epididymidis. The elevated immune response in the cauda prompts immunopathological alterations that can impair fertility. Although the caput is principally immunoreactive and the constituting cells can respond to inflammatory stimuli, the magnitude is at a much lesser extent. The data thus far have illustrated that strategically positioned MP subpopulations as well as region-specific expression of diverse immunomodulatory factors enable a precisely tuned balance between tolerance and defense at the opposing ends of the very same duct. Finally, the $\mathrm{BEB}$ seems to confer protection throughout the length of the epididymal duct, particularly from autoimmunity to sperm neoantigens. Going forward, research is necessary to better understand how this organ is able to maintain tolerance to autoimmunogenic spermatozoa at one end of the duct and ensure protection from ascending microbes at the other end. Then, work is warranted to delineate the functions of leukocytes in the steady-state epididymis, which currently remain an enigma.

\section{AUTHOR CONTRIBUTIONS}

$\mathrm{CP}, \mathrm{ES}, \mathrm{AP}, \mathrm{SB}$, and $\mathrm{AM}$ performed literature research and wrote the manuscript. All authors contributed to the article and approved the submitted version.

\section{FUNDING}

This work was supported by a GRK 1871/2 International Research Training Group Giessen-Monash grant on "Molecular pathogenesis of male reproductive disorders" (AM, $\mathrm{CP}, \mathrm{AP}$, and $\mathrm{SB}$ ) and a project grant $\mathrm{BH}$ 93/1-4 (awarded to $\mathrm{SB}$ ) from the Deutsche Forschungsgemeinschaft.

4. Shum WW, Smith TB, Cortez-Retamozo V, Grigoryeva LS, Roy JW, Hill E, et al. Epithelial basal cells are distinct from dendritic cells and macrophages in the mouse epididymis. Biol Reprod (2014) 90:90. doi: 10.1095/ biolreprod.113.116681

5. Robaire B, Hinton B, Orgebincrist M. The Epididymis. In: Knobil and Neill"s Physiology of Reproduction. (Amsterdam, Boston: Elsevier Academic Press) (2006). p. 1071-148.

6. Skerget S, Rosenow MA, Petritis K, Karr TL. Sperm Proteome Maturation in the Mouse Epididymis. PloS One (2015) 10:e0140650. doi: 10.1371/ journal.pone.0140650

7. Shum WW, Ruan YC, Da Silva N, Breton S. Establishment of cell-cell cross talk in the epididymis: control of luminal acidification. J Androl (2011) 32:576-86. doi: 10.2164/jandrol.111.012971 
8. Gregory M, Cyr DG. The blood-epididymis barrier and inflammation. Spermatogenesis (2014) 4:e979619. doi: 10.4161/21565562.2014.979619

9. Domeniconi RF, Souza AC, Xu B, Washington AM, Hinton BT. Is the Epididymis a Series of Organs Placed Side By Side? Biol Reprod (2016) 95:10. doi: 10.1095/biolreprod.116.138768

10. Battistone MA, Mendelsohn AC, Spallanzani RG, Brown D, Nair AV, Breton S. Region-specific transcriptomic and functional signatures of mononuclear phagocytes in the epididymis. Mol Hum Reprod (2020) 26:14-29. doi: 10.1093/molehr/gaz059

11. Voisin A, Whitfield M, Damon-Soubeyrand C, Goubely C, Henry-Berger J, Saez F, et al. Comprehensive overview of murine epididymal mononuclear phagocytes and lymphocytes: Unexpected populations arise. J Reprod Immunol (2018) 126:11-7. doi: 10.1016/j.jri.2018.01.003

12. Guiton R, Voisin A, Henry-Berger J, Saez F, Drevet JR. Of vessels and cells: the spatial organization of the epididymal immune system. Andrology (2019) 7:712-8. doi: 10.1111/andr.12637

13. Da Silva N, Cortez-Retamozo V, Reinecker H-C, Wildgruber M, Hill E, Brown D, et al. A dense network of dend1ritic cells populates the murine epididymis. Reproduction (2011) 141:653-63. doi: 10.1530/REP-10-0493

14. Klein B, Bhushan S, Günther S, Middendorff R, Loveland KL, Hedger MP, et al. Differential tissue-specific damage caused by bacterial epididymoorchitis in the mouse. Mol Hum Reprod (2020) 26:215-27. doi: 10.1093/ molehr/gaaa011

15. Rinaldi VD, Donnard E, Gellatly KJ, Rasmussen M, Kucukural A, Yukselen O, et al. An atlas of cell types in the mouse epididymis and vas deferens. Elife (2020) e:55474. doi: 10.7554/eLife.55474

16. Stammler A, Hau T, Bhushan S, Meinhardt A, Jonigk D, Lippmann T, et al. Epididymitis: ascending infection restricted by segmental boundaries. Hum Reprod (2015) 30:1557-65. doi: 10.1093/humrep/dev112

17. Turner TT, Bomgardner D, Jacobs JP, Nguyen QA. Association of segmentation of the epididymal interstitium with segmented tubule function in rats and mice. Reproduction (2003) 125:871-8. doi: 10.1530/rep.0.1250871

18. Pierucci-Alves F, Midura-Kiela MT, Fleming SD, Schultz BD, Kiela PR. Transforming Growth Factor Beta Signaling in Dendritic Cells Is Required for Immunotolerance to Sperm in the Epididymis. Front Immunol (2018) 9:1882:1882. doi: 10.3389/fimmu.2018.01882

19. Fijak M, Pilatz A, Hedger MP, Nicolas N, Bhushan S, Michel V, et al. Infectious, inflammatory and 'autoimmune' male factor infertility: how do rodent models inform clinical practice? Hum Reprod Update (2018) 24:41641. doi: 10.1093/humupd/dmy009

20. Flickinger CJ, Bush LA, Howards SS, Herr JC. Distribution of leukocytes in the epithelium and interstitium of four regions of the Lewis rat epididymis. Anat $\operatorname{Rec}$ (1997) 248:380-90. doi: 10.1002/(SICI)1097-0185(199707)248:3<380: AID-AR11>3.0.CO;2-L

21. Serre V, Robaire B. Distribution of immune cells in the epididymis of the aging Brown Norway rat is segment-specific and related to the luminal content. Biol Reprod (1999) 61:705-14. doi: 10.1095/biolreprod61.3.705

22. Nashan D, Malorny U, Sorg C, Cooper T, Nieschlag E. Immuno-competent cells in the murine epididymis. Int J Androl (1989) 12:85-94. doi: 10.1111/ j.1365-2605.1989.tb01289.x

23. Seiler P, Wenzel I, Wagenfeld A, Yeung CH, Nieschlag E, Cooper TG. The appearance of basal cells in the developing murine epididymis and their temporal expression of macrophage antigens. Int J Androl (1998) 21:217-26. doi: 10.1046/j.1365-2605.1998.00116.x

24. Da Silva N, Smith TB. Exploring the role of mononuclear phagocytes in the epididymis. Asian J Androl (2015) 17:591-6. doi: 10.4103/1008-682X.153540

25. Da Silva N, Barton CR. Macrophages and dendritic cells in the post-testicular environment. Cell Tissue Res (2016) 363:97-104. doi: 10.1007/s00441-0152270-0

26. Tamoutounour S, Henri S, Lelouard H, de Bovis B, de Haar C, van der Woude CJ, et al. CD64 distinguishes macrophages from dendritic cells in the gut and reveals the Th1-inducing role of mesenteric lymph node macrophages during colitis. Eur J Immunol (2012) 42:3150-66. doi: 10.1002/eji.201242847

27. McGovern N, Schlitzer A, Janela B, Ginhoux F. Protocols for the Identification and Isolation of Antigen-Presenting Cells in Human and Mouse Tissues. Methods Mol Biol (2016) 1423:169-80. doi: 10.1007/978-1-4939-3606-9_12

28. Hedger MP. Immunophysiology and pathology of inflammation in the testis and epididymis. J Androl (2011) 32:625-40. doi: 10.2164/jandrol.111.012989
29. Wang YF, Holstein AF. Intraepithelial lymphocytes and macrophages in the human epididymis. Cell Tissue Res (1983) 233:517-21. doi: 10.1007/ BF00212221

30. Duan Y-G, Wang P, Zheng W, Zhang Q, Huang W, Jin F, et al. Characterisation of dendritic cell subsets in chronically inflamed human epididymis. Andrologia (2016) 48:431-40. doi: 10.1111/and.12463

31. Ritchie AW, Hargreave TB, James K, Chisholm GD. Intra-epithelial lymphocytes in the normal epididymis. A mechanism for tolerance to sperm auto-antigens? Br J Urol (1984) 56:79-83. doi: 10.1111/j.1464410x.1984.tb07169.x

32. el-Demiry MI, Hargreave TB, Busuttil A, James K, Ritchie AW, Chisholm GD. Lymphocyte sub-populations in the male genital tract. Br J Urol (1985) 57:769-74. doi: 10.1111/j.1464-410x.1985.tb07051.x

33. Yakirevich E, Yanai O, Sova Y, Sabo E, Stein A, Hiss J, et al. Cytotoxic phenotype of intra-epithelial lymphocytes in normal and cryptorchid human testicular excurrent ducts. Hum Reprod (2002) 17:275-83. doi: 10.1093/ humrep/17.2.275

34. Michel V, Duan Y, Stoschek E, Bhushan S, Middendorff R, Young JM, et al. Uropathogenic Escherichia coli causes fibrotic remodelling of the epididymis. J Pathol (2016) 240:15-24. doi: 10.1002/path.4748

35. Wijayarathna R, Pasalic A, Nicolas N, Biniwale S, Ravinthiran R, Genovese R, et al. Region-specific immune responses to autoimmune epididymitis in the murine reproductive tract. Cell Tissue Res (2020) 381(2):351-60. doi: 10.1007/ s00441-020-03215-8

36. Pilatz A, Hossain H, Kaiser R, Mankertz A, Schüttler CG, Domann E, et al. Acute epididymitis revisited: impact of molecular diagnostics on etiology and contemporary guideline recommendations. Eur Urol (2015) 68:428-35. doi: 10.1016/j.eururo.2014.12.005

37. Çek M, Sturdza L, Pilatz A. Acute and Chronic Epididymitis. Eur Urol Suppl (2017) 16:124-31. doi: 10.1016/j.eursup.2017.01.003

38. Wolin LH. On the Etiology of Epididymitis. J Urol (1971) 105:531-3. doi: $10.1016 / \mathrm{S} 0022-5347(17) 61567-2$

39. Wesselhoeft C. Orchitis in Mumps. Boston Med Surg J (1920) 183:458-61. doi: 10.1056/NEJM192010141831602

40. Park SJ, Kim HC, Lim JW, Moon SK, Ahn SE. Distribution of Epididymal Involvement in Mumps Epididymo-orchitis. J Ultrasound Med (2015) 34:1083-9. doi: 10.7863/ultra.34.6.1083

41. Rival C, Wheeler K, Jeffrey S, Qiao H, Luu B, Tewalt EF, et al. Regulatory T cells and vasectomy. J Reprod Immunol (2013) 100:66-75. doi: 10.1016/ j.jri.2013.08.004

42. Mazzini E, Massimiliano L, Penna G, Rescigno M. Oral tolerance can be established via gap junction transfer of fed antigens from CX3CR $1_{+}$ macrophages to $\mathrm{CD} 103^{+}$dendritic cells. Immunity (2014) 40:248-61. doi: 10.1016/j.immuni.2013.12.012

43. Worbs T, Bode U, Yan S, Hoffmann MW, Hintzen G, Bernhardt G, et al. Oral tolerance originates in the intestinal immune system and relies on antigen carriage by dendritic cells. J Exp Med (2006) 203:519-27. doi: 10.1084/ jem.20052016

44. Smith TB, Cortez-Retamozo V, Grigoryeva LS, Hill E, Pittet MJ, Da Silva N. Mononuclear phagocytes rapidly clear apoptotic epithelial cells in the proximal epididymis. Andrology (2014) 2:755-62. doi: 10.1111/j.20472927.2014.00251.x

45. Raymond AS, Shur BD. A novel role for SED1 (MFG-E8) in maintaining the integrity of the epididymal epithelium. J Cell Sci (2009) 122:849-58. doi: $10.1242 /$ jcs. 041731

46. Wheeler K, Tardif S, Rival C, Luu B, Bui E, Del Rio R, et al. Regulatory T cells control tolerogenic versus autoimmune response to sperm in vasectomy. Proc Natl Acad Sci U.S.A. (2011) 108:7511-6. doi: 10.1073/pnas.1017615108

47. Voisin A, Damon-Soubeyrand C, Bravard S, Saez F, Drevet JR, Guiton R. Differential expression and localisation of TGF- $\beta$ isoforms and receptors in the murine epididymis. Sci Rep (2020) 10:995. doi: 10.1038/s41598-02057839-5

48. Shi Y, Massagué J. Mechanisms of TGF- $\beta$ Signaling from Cell Membrane to the Nucleus. Cell (2003) 113:685-700. doi: 10.1016/S0092-8674(03)00432-X

49. Jrad-Lamine A, Henry-Berger J, Gourbeyre P, Damon-Soubeyrand C, Lenoir A, Combaret L, et al. Deficient tryptophan catabolism along the kynurenine pathway reveals that the epididymis is in a unique tolerogenic state. J Biol Chem (2011) 286:8030-42. doi: 10.1074/jbc.M110.172114 
50. Wijayarathna R, Kretser DM, Sreenivasan R, Ludlow H, Middendorff R, Meinhardt A, et al. Comparative analysis of activins A and B in the adult mouse epididymis and vas deferens. Reproduction (2018) 155:15-23. doi: 10.1530/REP-17-0485

51. Hall SH, Yenugu S, Radhakrishnan Y, Avellar MC, Petrusz P, French FS. Characterization and functions of beta defensins in the epididymis. Asian J Androl (2007) 9:453-62. doi: 10.1111/j.1745-7262.2007.00298.x

52. Ribeiro CM, Silva EJ, Hinton BT, Avellar MC. $\beta$-defensins and the epididymis: contrasting influences of prenatal, postnatal, and adult scenarios. Asian J Androl (2016) 18:323-8. doi: 10.4103/1008-682X.168791

53. Battistone MA, Spallanzani RG, Mendelsohn AC, Capen D, Nair AV, Brown $\mathrm{D}$, et al. Novel role of proton-secreting epithelial cells in sperm maturation and mucosal immunity. J Cell Sci (2019) 133(5):jcs233239. doi: 10.1242/ jcs.233239

54. Wijayarathna R, Hedger MP. Activins, follistatin and immunoregulation in the epididymis. Andrology (2019) 7:703-11. doi: 10.1111/andr.12682

55. Greskovich F, Mathur S, Nyberg LM, Collins BS. Effect of early antibiotic treatment on the formation of sperm antibodies in experimentally induced epididymitis. Arch Androl (1993) 30:183-91. doi: 10.3109/ 01485019308987755

56. Vieler E, Jantos C, Schmidts HL, Weidner W, Schiefer HG. Comparative efficacies of ofloxacin, cefotaxime, and doxycycline for treatment of experimental epididymitis due to Escherichia coli in rats. Antimicrob Agents Chemother (1993) 37:846-50. doi: 10.1128/aac.37.4.846

57. Ludwig M, Johannes S, Bergmann M, Failing K, Schiefer HG, Weidner W. Experimental Escherichia coli epididymitis in rats: a model to assess the outcome of antibiotic treatment. BJU Int (2002) 90:933-8. doi: 10.1046/j.1464410x.2002.03029.x

58. Ludwig M. Diagnosis and therapy of acute prostatitis, epididymitis and orchitis. Andrologia (2008) 40:76-80. doi: 10.1111/j.1439-0272.2007.00823.x

59. Klein B, Pant S, Bhushan S, Kautz J, Rudat C, Kispert A, et al. Dexamethasone improves therapeutic outcomes in a preclinical bacterial epididymitis mouse model. Hum Reprod (2019) 34:1195-205. doi: 10.1093/humrep/dez073

60. Palladino MA, Savarese MA, Chapman JL, Dughi M-K, Plaska D. Localization of Toll-like receptors on epididymal epithelial cells and spermatozoa. Am J Reprod Immunol (2008) 60:541-55. doi: 10.1111/j.1600-0897.2008.00654.x

61. Rodrigues A, Queiróz DB, Honda L, Silva EJ, Hall SH, Avellar MC. Activation of toll-like receptor 4 (TLR4) by in vivo and in vitro exposure of rat epididymis to lipopolysaccharide from Escherichia Coli. Biol Reprod (2008) 79:1135-47. doi: 10.1095/biolreprod.108.069930

62. Cheng L, Chen Q, Zhu W, Wu H, Wang Q, Shi L, et al. Toll-like Receptors 4 and 5 Cooperatively Initiate the Innate Immune Responses to Uropathogenic
Escherichia coli Infection in Mouse Epididymal Epithelial Cells. Biol Reprod (2016) 94:58. doi: 10.1095/biolreprod.115.136580

63. Özbek M, Hitit M, Ergün E, Ergün L, Beyaz F, Erhan F, et al. Expression profile of Toll-like receptor 4 in rat testis and epididymis throughout postnatal development. Andrologia (2020) 52:e13518. doi: 10.1111/and.13518

64. Robertson MJ, Kent K, Tharp N, Nozawa K, Dean L, Mathew M, et al. Largescale discovery of male reproductive tract-specific genes through analysis of RNA-seq datasets. BMC Biol (2020) 18:103. doi: 10.1186/s12915-020-00826-z 65. Silva EJ, Queiróz DB, Rodrigues A, Honda L, Avellar MC. Innate immunity and glucocorticoids: potential regulatory mechanisms in epididymal biology. J Androl (2011) 32:614-24. doi: 10.2164/jandrol.111.013565

66. Wang F, Liu W, Jiang Q, Gong M, Chen R, Wu H, et al. Lipopolysaccharideinduced testicular dysfunction and epididymitis in mice: a critical role of tumor necrosis factor alpha†. Biol Reprod (2019) 100:849-61. doi: 10.1093/ biolre/ioy 235

67. Silva EJ, Ribeiro CM, Mirim AF, Silva AA, Romano RM, Hallak J, et al. Lipopolysaccharide and lipotheicoic acid differentially modulate epididymal cytokine and chemokine profiles and sperm parameters in experimental acute epididymitis. Sci Rep (2018) 8:103. doi: 10.1038/s41598-017-17944-4

68. Song X, Lin N-H, Wang Y-L, Chen B, Wang H-X, Hu K. Comprehensive transcriptome analysis based on RNA sequencing identifies critical genes for lipopolysaccharide-induced epididymitis in a rat model. Asian J Androl (2019) 21:605-11. doi: 10.4103/aja.aja-21-19

69. Cao D, Li Y, Yang R, Wang Y, Zhou Y, Diao H, et al. Lipopolysaccharideinduced epididymitis disrupts epididymal beta-defensin expression and inhibits sperm motility in rats. Biol Reprod (2010) 83:1064-70. doi: 10.1095/ biolreprod.109.082180

70. Wu Y, Li H, Qin Y. S100A4 Promotes the Progression of Lipopolysaccharideinduced Acute Epididymitis in Mice†. Biol Reprod (2020) 102(6):1213-24. doi: 10.1093/biolre/ioaa022

Conflict of Interest: The authors declare that the research was conducted in the absence of any commercial or financial relationships that could be construed as a potential conflict of interest.

Copyright (c) 2020 Pleuger, Silva, Pilatz, Bhushan and Meinhardt. This is an openaccess article distributed under the terms of the Creative Commons Attribution License (CC BY). The use, distribution or reproduction in other forums is permitted, provided the original author(s) and the copyright owner(s) are credited and that the original publication in this journal is cited, in accordance with accepted academic practice. No use, distribution or reproduction is permitted which does not comply with these terms. 